\title{
Value of Calcium and Phosphorous in chronic kidney disease patients under hemodialysis: A retrospective study
}

\author{
Singh $\mathrm{S}^{1}$, Upadhyay-Dhungel $\mathrm{K}^{2}$, Aryal $\mathrm{G}^{3}$ \\ ${ }^{I}$ Department of Biochemistry, KIST Medical College, Lalitpur, Nepal \\ ${ }^{2}$ Department of Physiology, KIST Medical College, Lalitpur, Nepal \\ ${ }^{3}$ Department of Pathology, KIST Medical College, Lalitpur, Nepal
}

\section{Keywords:}

Calcium; Hemodialysis; K/DOQI;

Phosphorus

\begin{abstract}
Background: Derangements of mineral metabolism occur during early stages of chronic kidney disease (CKD). Mineral metabolism has emerged as important predictors of morbidity and mortality in dialysis patients. This study aims to evaluate the values of calcium and phosphorous in reference to practice guidelines issued by National Kidney Foundation Dialysis Outcomes Quality Initiative (K/DOQI) in patients undergoing hemodialysis in KIST Medical College Teaching Hospital.
\end{abstract}

Materials and Methods: It was a retrospective study which included 101 patients who underwent hemodialysis in KIST Medical College Teaching Hospital over a period of three months (October 2010 to December 2010). The laboratory parameters of serum calcium, and phosphorus were evaluated and were compared with that of recommended values by K/DOQI guidelines.

Results: The mean values for serum calcium, phosphorus, and calcium-phosphorus product were 8.79 $\pm 1.48 \mathrm{mg} / \mathrm{dL}, 5.30 \pm 1.32 \mathrm{mg} / \mathrm{dL}$ and $46.62 \pm 1.96 \mathrm{mg} 2 / \mathrm{dL} 2$ respectively. Forty (40\%), 53 (53\%) and $76(76 \%)$ cases of CKD patients met K/DOQI target value for calcium, phosphorous and calciumphosphorous product respectively. Twenty one percent of the patients meet the three K/DOQI guidelines and $14 \%$ did not meet any of the recommended guidelines by K/DOQI.

Conclusion: To achieve all the K/DOQI guidelines multi-disciplinary team approach is crucial. More extensive multicenter studies need to be carried out. It is necessary to develop our national guidelines in future.

\section{INTRODUCTION}

A chronic kidney disease (CKD) is emerging as one of the major public health problems across the world and its incidence is rising day by day. ${ }^{1}$ CKD may lead to end-stage renal disease (ESRD) and is also associated with increased

\section{Correspondence:}

\section{Mr. Samir Singh, Lecturer}

Department of Biochemistry, KIST Medical College, Lalitpur, Nepal

E-mail: samirbiochem_13@yahoo.co.in risk of cardiovascular disease, heart failure, and increased healthcare expenditures. ${ }^{2}$

Mineral metabolism has emerged as important predictors of morbidity and mortality in dialysis patients. ${ }^{3}$ Disturbances in calcium and phosphorus is commonly observed in patients with CKD. Renal osteodystrophy, a metabolic bone disease usually accompanies CKD. It is the result of hyperparathyroidism secondary to hyperphosphatemia 


\begin{tabular}{|c|c|c|}
\hline Variables & Mean & SD \\
\hline Calcium (mg/dL) & 8.79 & 1.48 \\
\hline Phosphorus (mg/dL) & 5.3 & 1.32 \\
\hline
\end{tabular}

Table 2: Comparison of laboratory values with K/DOQI target ranges for mineral metabolism

\begin{tabular}{lc}
\hline Factor and K/DOQI ranges & Patient percentage $\dagger$ \\
\hline Serum Calcium $(\mathrm{mg} / \mathrm{dL})$ & 29 \\
$<8.4$ & 40 \\
$8.4-9.5 \ddagger$ & 32 \\
$>9.5$ & \\
\hline Serum Phosphorous $(\mathrm{mg} / \mathrm{dL})$ & 6 \\
$<3.5$ & 53 \\
$3.5-5.5 \ddagger$ & 42 \\
$>5.5$ & \\
\hline Calcium-Phosphorous Product (mg2/dL2) & 76 \\
$<55 \ddagger$ & 23 \\
$55-72$ & 2 \\
$>72$ & \\
\hline$\dagger$, percentages are roundup to the nearest figure \\
$\ddagger$ K/DOQI target value
\end{tabular}

Table 3: Achievement of K/DOQI guideline targets for mineral metabolism

\begin{tabular}{lc}
\hline Status & Patients (\%) \\
\hline None of the targets achieved & 14 \\
At least one of the target achieved & 87 \\
At least two of the target achieved & 59 \\
Three of three target considered achieved & 21 \\
\hline
\end{tabular}

combined with hypocalcaemia, both of which are due to decreased excretion of phosphate by the damaged kidney. Healthy kidneys convert inactive vitamin D to its active metabolite, 1,25 dihydroxycholecalciferol. If renal functioning is affected, the production of 1,25 dihydroxycholecalciferol reduces that leads to hypocalcaemia because less calcium is absorbed from the intestine. In addition, the renal clearance of phosphorus decreases with a deteriorating kidney function and phosphorus concentrations increase. Hypocalcaemia in its turn leads to an increased production of parathyroid hormone (PTH) by the parathyroid glands, which is called secondary hyperparathyroidism. ${ }^{4}$

There is no documented data related to mineral metabolism outcomes in Hemodialysis (HD) patients in Nepal. Several expert panels have issued management guidelines for the management of altered mineral metabolism in dialysis patients. Among them, the guidelines published in 2003 by K/DOQI, recommended the serum levels of phosphorus between 3.5-5.5 mg/dl; serum calcium 8.4-9.5 mg/dl and calcium-phosphorus product, $<55 \mathrm{mg}^{2} / \mathrm{dl}^{2}$, and serum PTH, between $150-300 \mathrm{pg} / \mathrm{ml} .^{5}$ This study aims to evaluate the values of calcium and phosphorous in reference to practice guidelines recommended by $\mathrm{K} / \mathrm{DOQI}$ in patients undergoing HD in KIST Medical College Teaching Hospital (KISTMCTH), Nepal.

\section{MATERIALS AND METHODS}

We retrospectively evaluated the laboratory parameters of serum calcium, and phosphorus from 101 (62 male and 39 female) patients who underwent HD at KISTMCTH over three months period from October 2010 to December 2010. The calcium and phosphorous evaluation was done by using Biochemical semi-analyzer (STATFAX 3000). The values of serum calcium, phosphorus and calcium-phosphorus product were compared with $\mathrm{K} / \mathrm{DOQI}$ guidelines. ${ }^{5}$

\section{RESULTS}

Out of 101 patients, 62 were male and 39 were female. Age ranged from 20 to 80 years. Average age of the study population was $48.36 \pm 17.94$ years. Seventy two percent of the patients were between the ages of 20-60 years. The mean duration of HD session was $3.95 \pm 0.42$ hours. The mean number of HD session per week was $2.08 \pm 0.46$ days. Patients were given phosphate binders (calcium carbonate and/or calcium acetate and/or lanthanum carbonate) depending upon their status of serum calcium level, phosphorous level and clinical condition.

Serum value of calcium and phosphorus is presented in Table 1 . Table 2 depicts the comparison of laboratory tests results in patients on $\mathrm{HD}$ with $\mathrm{K} / \mathrm{DOQI}$ target ranges for mineral metabolism. Twenty one percent of the patients met the three considered guidelines successfully and $14 \%$ did not meet any of the recommended guidelines as shown in Table 3.

\section{DISCUSSION}

Abnormal mineral metabolism start early in course of CKD and ESRD, and is usually accompanied by profound changes in mineral metabolism that leads to clinical problems such as bone diseases, musculoskeletal symptoms and growth retardation. Recent study has found a strong association between mortality and abnormal mineral metabolism; presumably mediated by vascular calcification. ${ }^{6}$ The disturbances include calcium, phosphate, vitamin $\mathrm{D}$, and PTH homeostasis. So, mineral metabolism outcomes are gaining importance in HD treatment. Hyperphosphatemia is one of the major factors responsible for alterations in mineral and bone metabolism in dialysis patients. ${ }^{7}$ In our study, the control of serum phosphorus values was adequate in $53 \%$ of patients undergoing $\mathrm{HD}$, while $42 \%$ of the patients presented with hyperphosphatemia. These findings are 
comparable to the study in Iran by Mahdavi-Mazdeh et al. ${ }^{8}$ Hyperphosphatemia occurs as a consequence of diminished phosphorous filtration and excretion with the progression of CKD. Decrease phosphorus excretion can initially be overcome by increase secretion of PTH which decreases proximal phosphate reabsorption. Hence phosphorus levels are usually within normal range until glomerular filtration rate (GFR) falls below approximately $30 \mathrm{~mL} / \mathrm{min}$ or CKD4 according to $\mathrm{K} / \mathrm{DOQI}$ classification. In more advanced stage of CKD, the urinary excretion of phosphorus can no longer keep pace with the obligatory intestinal phosphate absorption resulting in hyperphosphatemia. The recent finding suggests that elevated serum phosphorus is associated with an increase risk for cardiovascular mortality and morbidity among dialysis patients. ${ }^{9}$ The consequences of hyperphosphatemia include the development and progression of secondary hyperparathyroidism and a predisposition to metastatic calcification when the product of serum calcium and phosphorus is elevated. Both of these conditions may contribute to the substantial morbidity and mortality seen in patients with ESRD. ${ }^{6}$ In our study, $29 \%$ were hypocalcemic $(<8.4)$ and the K/DOQI guidelines for calcium was achieved in $40 \%$ of the patients. However $32 \%$ patients had their calcium level above K/DOQI guidelines. Similarly the product of serum calcium and phosphorus was elevated in $24 \%$.

A study by Schwartz et al showed an association between higher levels of serum phosphorus and calcium-phosphorus product with an unfavorable renal outcome. ${ }^{10}$ In their study higher serum phosphorus was associated with significantly higher risk for progression of CKD, even after adjustment for multiple potential confounders. The association of higher serum phosphorus with progressive CKD was more accentuated in patients with higher serum calcium levels also supports the hypothesis that tissue calcification may be the reason behind the observed associations. This association seems now to involve active steps at the cellular and subcellular levels, with hyperphosphatemia shown to be associated with increased expression of osteoblast-specific proteins in vascular smooth muscle cells. ${ }^{11-13}$ Reynolds et al showed that higher ambient serum calcium level led to more significant phosphorus-driven calcification of vascular smooth muscle in vitro. ${ }^{14}$

In this study, most of patients were in age group between $20-60$ years of age. In developed world, mean age of CKD5 leading to ESRD is between 60-63 years. In our study, average age of presentation was around 48 years which is similar to median age of 43 years in India. ${ }^{15}$

In this study, only $21 \%$ of the patients met the three considered guidelines of mineral metabolism outcomes after dialysis successfully and $14 \%$ did not meet any of the recommended guidelines. This is similar to other studies. ${ }^{916}$

Regular dialysis treatment is unble to remove all the phosphorous ingested with a diet containing sufficient amount of protein to avoid malnutrition. In this regards, our patients were taking phosphate binders such as calcium carbonate, calcium acetate and lanthanum carbonate to decrease dietary phosphorous depending upon their serum calcium and phosphorus levels. The treatment with these calcium-based phosphate binders is not free from complications such as hypercalcaemia. The noncalcium phosphate binder such as lanthanum carbonate is an effective and well tolerated agent for the treatment of hyperphosphatemia in patients with ESRD. Therefore, the strict maintenance of serum calcium and phosphorus levels within the ranges recommended by the K/DOQI guidelines is difficult to achieve due to these multifactorial reasons. ${ }^{17-20}$

Craver et al argue and emphasize on the fact that data from CKD patients from one population may not apply to other population due to differences in social, ethnic and health system characteristics as well as nutritional habits. ${ }^{21}$

\section{CONCLUSION}

To achieve all the K/DOQI guidelines, multi-disciplinary team approach is crucial. We emphasize on the need of large scale multi-centre study of mineral metabolism of CKD patients in Nepal. This will be helpful in establishing our own local guidelines in future.

\section{REFERENCES}

1. Khakurel S, Agrawal RK, Hada R. Pattern of End Stage Renal Disease in a Tertiary Care Center. J Nepal Med Assoc 2009;48:12630.

2. Weiss JW, Petrik AF, Thorp ML. Identification and Management of Chronic Kidney Disease in Older Adults. Clinical Geriatrics 2011;19:33-7.

3. Block GA, Klassen PS, Lazarus JM, Ofsthun N, Lowrie FG, Chertow GM. Mineral metabolism, mortality, and morbidity in maintenance hemodialysis. J Am Soc Nephrol 2004;15:2208-18.

4. Colledge NK, Walker BR, Ralston SH. Davidson's Principles and Practice of Medicine. 21st ed. Churchill Livingstone Elsevier; 2010. pp 487-92.

5. National Kidney Foundation. K/DOQI clinical practice guidelines for bone metabolism and disease in chronic kidney disease. Am J Kidney Dis 2003;42:S1-201.

6. Block GA, Hulbert-Shearon TE, Levin NW, Port FK. Association of serum phosphorus and calcium $\mathrm{x}$ phosphate product with mortality risk in chronic hemodialysis patients: A national study. Am J Kidney Dis 1998;31:607-17.

7. Panichi V, Bigazzi R, Paoletti S et al. Impact of calcium, phosphate, PTH abnormalities and management on mortality in hemodialysis: Results from the RISCAVID study. J Nephrol 2010;23:556-62.

8. Mahdavi-Mazdeh M, Zamyadi M, Norouzi S, Heidary Rouchi A. Management of Calcium and Phosphorus Metabolism in Hemodialysis Patients in Tehran Province, Iran. Iran J Kidney Dis 2007;1:25-8.

9. Coladonato JA. Control of hyperphosphatemia among patients with ESRD. J Am Soc Nephrol 2005;16:S107-14.

10. Schwarz S, Trivedi BK, Kalantar-Zadeh K, Kovesdy CP. Association of Disorders in Mineral Metabolism with Progression of Chronic 
Kidney Disease. Clin J Am Soc Nephrol 2006;1:825-31.

11. Bostrom K. Insights into the mechanism of vascular calcification. Am J Cardiol 2001;88:20E -22E.

12. Jono $\mathrm{S}, \mathrm{McKee} \mathrm{MD}$, Murry $\mathrm{CE}$ et al. Phosphate regulation of vascular smooth muscle cell calcification. Circ Res 2000;87:E10-7.

13. Qunibi WY, Nolan CA, Ayus JC. Cardiovascular calcification in patients with end-stage renal disease: A century-old phenomenon. Kidney Int Suppl 2002;82:S73-80.

14. Reynolds JL, Joannides AJ, Skepper JN et al. Human vascular smooth muscle cells undergo vesicle-mediated calcification in response to changes in extracellular calcium and phosphate concentrations: A potential mechanism for accelerated vascular calcification in ESRD. J Am Soc Nephrol 2004;15:2857-67.

15. Chhetri PK, Manandhar DN, Bhattarai SP, Pahari LR, Shrestha R. Chronic kidney disease 5 on hemodialysis in Nepal Medical College Teaching Hospital. Nepal Med Coll J 2008;10:8-10.
16. Al Aly Z, González EA, Martin KJ, Gellens ME. Achieving K/DOQI laboratory target values for bone and mineral metabolism: an uphill battle. Am J Nephrol 2004;24:422-6.

17. Gal-Moscovici A, Sprague SM. Bone health in chronic kidney disease-mineral and bone disease. Adv Chronic Kidney Dis 2007;14:27-36.

18. Bellasi A, Kooienga L, Block GA. Phosphate binders: new products and challenges. Hemodial Int 2006;10:225-34.

19. Maduell F, Gorriz JL, Pallardo LM et al. Assessment of phosphorus and calcium metabolism and its clinical management in hemodialysis patients in the community of Valencia. J Nephrol 2005;18:739-48.

20. Savica V, Calò LA, Monardo $\mathrm{P}$ et al. Phosphate binders and management of hyperphosphataemia in end-stage renal disease. Nephrol Dial Transplant 2006;21:2065-8.

21. Craver L, Marco MP, Martínez I, Santoro D, Bellinghieri G. Mineral metabolism parameters throughout chronic kidney disease stages 1-5-achievement of K/DOQI target ranges. Nephrol Dial Transplant 2007;22:1171-76. 